\title{
Fat deposition in the left ventricle: descriptive and observacional study in autopsy
}

Ricella Maria Souza da Silva ${ }^{1,2^{*}}$ and Roberto José Vieira de Mello ${ }^{3}$

\begin{abstract}
Background: The human heart contains varying amounts of fat deposits. Cardiac physiological fat occurs predominantly in the right ventricle (RV). The discovery and characterization of adipose tissue along the left ventricle (LV) has been rarely reported. This study aimed to determine the occurrence of fatty deposits in epicardial, pericoronay and myocardial compartments in the LV, and to trace the epidemiological profile and clinical associations with this finding.

Methods: Epidemiological and morphological data and heart samples were collected from corpses submitted to necropsy. Cardiac samples were fixed, embedded in paraffin and subjected to hematoxylin-eosin for microscopic study.

Results: The research was based on 40 samples of cardiac tissue, 21 male cadavers and 19 female ones with mean age of 68.2 years. 52.2\% of the subjects had a history of smoking, $20 \%$ of them had alcohol consumption and 43. $59 \%$ showed cardiac cause as a cause of death (acute myocardial infarction - AMI - was the most frequent immediate cause of death). $82.5 \%$ of the subjects showed atherosclerotic disease in the ascending aorta (ADAA). The fat deposition in the left ventricule (FDLV) was observed in 95\% of cases. Epicardial fat (EF) and pericoronary adipose tissue (PAT) are the most frequent topographies in fat accumulation in the left heart chamber and the EF deposition is associated with myocardial adiposity (MA) (Fisher test [FT] 0.019; odds ratio [OR] 0.097 [95\% Cl 0.033 to 0.284]; $p<0.05$ ). FDLV was associated with alcoholism (FT 0.04, OR 0.161 [95\% Cl 0.072 to 0.36]; $p<0.05$ ); smoking (FT 0.508; OR 0581 [95\% Cl 0.431 to 0.73]; $p<0.05$ ), presence of Frank's sign (FT 0.502; OR 0.567 [95\% Cl 0.414 to 0. 775]; $p<0.05$ ); ADAA (0.774 OR [95\% Cl 0.6405 to 0.936]; $p<0.05$ ); AMI (OR 0.730 [95\% Cl 0.600 to 0.888]; $p<0.05$ ) and macroscopic finding of cardiac hypertrophy (OR 0.700 [95\% Cl 0.525 to 0.933]; $p<0.05$ ). FDLV is related with the thickness of the abdominal fat cushion.
\end{abstract}

Conclusions: FDLV is common and associated with cardiovascular disease risk factors. Cardiac adiposity cannot be considered a random autopsy finding, requiring diagnostic research and more studies to investigate the clinical implications.

Keywords: Adipose tissue, Heart, Necropsy

\footnotetext{
*Correspondence: ricellasouza@gmail.com

'Pathological Anatomy Service, Lauro Wanderley University Hospital, Federal

University of Paraíba, João Pessoa, Paraíba, Brazil

${ }^{2}$ Postgraduate Program in Pathology, Federal University of Pernambuco,

Recife, Brazil

Full list of author information is available at the end of the article
} 


\section{Background}

The human heart contains varying amounts of fat deposits [1]. Physiological cardiac fat can be separated into two compartments: extrapericardic and intrapericardic. Intrapericardial adipose tissue includes EF, PAT and MA [2].

Cardiac physiological fat predominantly occurs in the RV $[3,4]$ and is present in more than $50 \%$ of healthy elderly $[5,6]$. The degree of fat in the RV increases with age, and its development is considered part of the aging process [7]. Fat in the pathological myocardium is known to be seen in patients with various heart diseases, such as: healed myocardial infarction [8], right ventricular arrhythmogenic dysplasia [1,9] and some cardiomyopathies [10, 11].

The finding and characterization of adipose tissue along the LV in healthy individuals or individuals without a clinical history of heart disease has been rarely reported and remains little known $[9,10]$. In the last decade, especially due to the rapid development in the noninvasive imaging field, there has been increasing evidence regarding to the presence of fat cells in the myocardium [2].

The present study sought to determine the occurrence and characterization of fat deposits in the different compartments of the LV, tracing the epidemiological profile and clinical associations with this finding, in order to discuss the need for diagnostic and prophylactic investigation of FDLV.

\section{Methods}

\section{Type and study group}

Prospective, cross-sectional, descriptive and observational study. The research was performed with samples of cardiac tissue collected from corpses submitted to necropsy (adults over 18 years of age and of both genders) at the Death Verification Service (DVS) of Recife, an agency linked to the Health Department of the State of Pernambuco and agreed to the Federal University of Pernambuco, followed up for 1 month.

\section{Collect of data}

Data collection was performed using a specific preprepared form, using the anatomicopathological cadaveric report and the death certificate made at the time of the necropsy as data sources. Epidemiological and morphological information were collected during the usual necroscopic procedures of death verification (necropsy according to the precepts of the Virchow technique).

The epidemiological data analyzed were: sex; age; pathological background; habits and customs (alcoholism, smoking); immediate cause and basic cause of death.

The morphological data were collected as: absence or presence (unilateral or bilateral) of the diagonal lobular fold; observation of the absence or presence of ADAA; measurement (with centimetric ruler and transparent millimeter) of the thickness of the adipose cushion of the abdominal wall at the height of the umbilical scar and main macroscopic cardiac findings.

\section{Collect of samples}

First, the heart was analyzed macroscopically, observing characteristics related to volume and consistency. The cardiac collection (concomitant to the method of finding the cause of death) followed the following norms: serial cross-sections using a cutting tool along the short axis of both ventricles to the tip of the papillary muscles.

The sections were made parallel to the atrioventricular groove at intervals of 1 to $1.5 \mathrm{~cm}$ from the apex of the heart, with the atrioventricular valve apparatus left intact in the remainder of the sample. For the histological analysis, the cardiac transverse slice resulting from the serial cuts, located in the ventricular midline and anatomically with the coronary artery, was selected and fixed in $10 \%$ formalin.

From the selected slice, it were collected a sample of the LV anterior wall and a sample of the posterior wall of the LV, placed in one or more histological cassettes (Fig. 1). These samples were submitted to automated

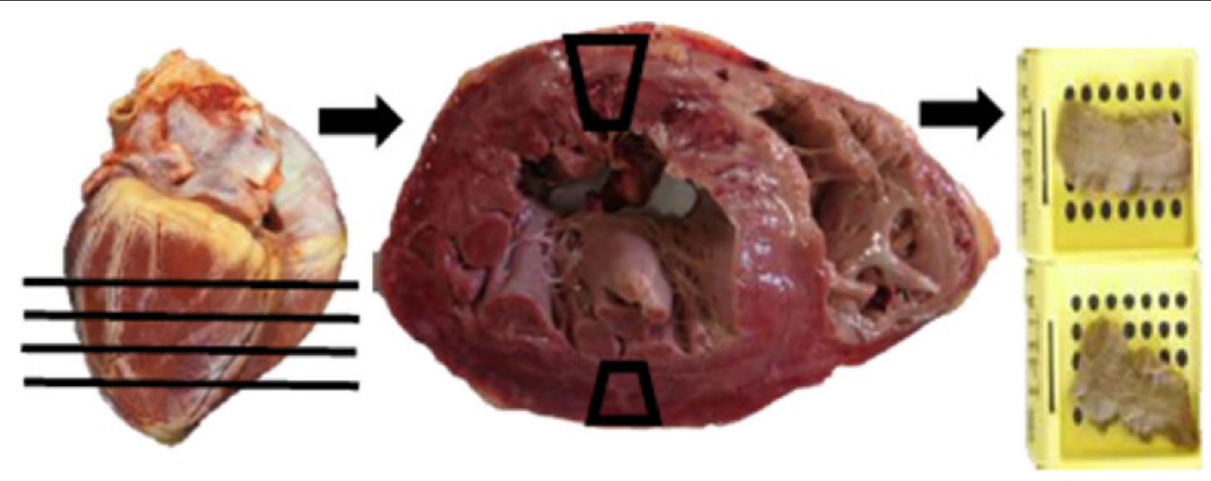

Fig. 1 Method of collection of cardiac samples in cadavers submitted to clinical necropsy 
Table 1 Pathological history of necropsied corpses in the DVS

\begin{tabular}{lll}
\hline & Frequency & Percentage \\
\hline Arterial hypertension & 14 & 35.0 \\
Cardiopathy & 1 & 2.5 \\
Depression & 1 & 2.5 \\
Diabetes mellitus & 11 & 27.5 \\
Eschar & 1 & 2.5 \\
HIV & 1 & 2.5 \\
Leprosy & 1 & 2.5 \\
Lower member amputation & 1 & 2.5 \\
Muscular dystrophy & 1 & 2.5 \\
No pathological background & 5 & 12.5 \\
Pancreatic neoplasia & 1 & 2.5 \\
Stroke & 2 & 5.0 \\
Total & 40 & 100.0 \\
\hline
\end{tabular}

histological processing, embedded in paraffin, sectioned, histological sections between 3 and $7 \mu \mathrm{m}$ thickness, collected on histological slide and stained with hematoxylin-eosin for microscopic study.

\section{Analysis of the samples}

Cardiac microscopic analysis consisted in: a) the identification of the presence of fatty deposition in the anterior and/or posterior wall of the LV; b) the characterization of this deposit in the different anatomical compartments: presence or absence of EF, PAT and MA - intercardiomyocytes; c) measurement with the microscopic ruler ( $0.5 \mathrm{~mm}$ and $10 \mathrm{~mm}$ scale) of the greatest thickness of the epicardial adipose deposit for each sample analyzed (microscopic analysis performed on an Olympus BX46 microscope, with Olympus SC30 camera imaging and thickness measurement with microscopic ruler linked to the CellSens Entry software 1.12).

\section{Ethical aspects}

All applicable international, national and/or institutional guidelines were followed. The execution of the present study was authorized by the General Directorate of Health Education of the Health Department of the State of Pernambuco, as well as approved by the Ethics and Research Committee of the Federal University of Pernambuco.

\section{Statistical analysis}

Statistical analysis was performed using SPSS software for Windows version 13.0. The Fisher test was applied for associations between groups of qualitative variables and obtained Risk Chance estimates. Statistical significance was defined as $p<0.05$.

\section{Results}

\section{Epidemiological analysis}

The research was based on 40 samples of cardiac tissue collected from corpses submitted to necropsy at the DVS of Recife. The study group included 21 male cadavers and 19 female cadavers aged between 35 and 96 years (mean of 68.2 years, median of 70.0 years). The most common pathological antecedent was Arterial Hypertension (35\%), followed by Diabetes Mellitus (27.5\%) (Table 1). In relation to habits and customs, $52.5 \%$ of the individuals had a history of smoking and $20 \%$ of alcoholism.

The most frequent immediate cause of death was AMI (10 cases), followed by sepsis (3 cases). The causes of death were as follows: $43.9 \%$, cardiac diseases; $24 \%$, diseases of the respiratory system; $13 \%$, some infectious or parasitic diseases; $11 \%$, diseases not classified elsewhere; and 5\% neoplasms.

\section{Macroscopic morphological analysis}

The diagonal lobular fold - Frank's sign - was found in 16 of the 40 cadavers analyzed, while $82.5 \%$ of the

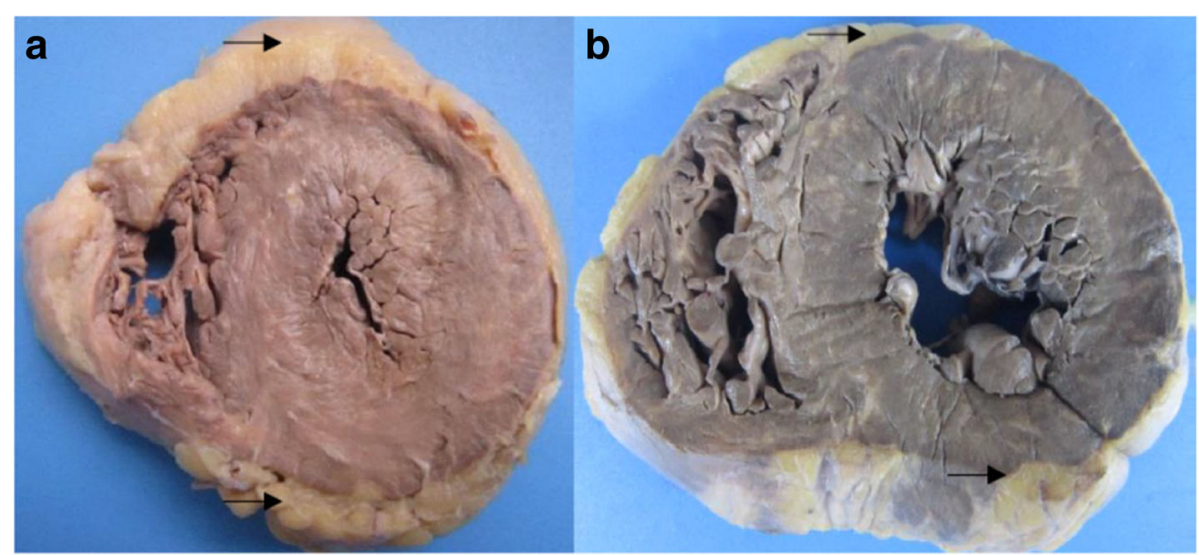

Fig. 2 Cross section of the heart with macroscopic view of FDLV (arrows). Legend: a Case 19; b Case 13 


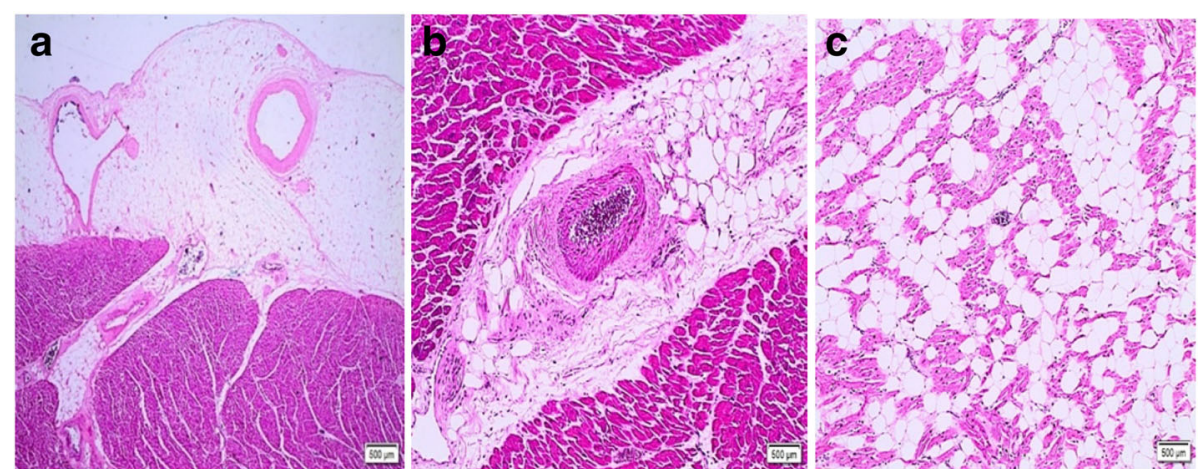

Fig. 3 Photomicrographs of cardiac samples showing adipose deposition in anatomical compartments of the LV. Legend: a EF (Case 1); $\mathbf{b}$ PAT (Case 5); c MA (Case 7). Hematoxilina-eosina; 4X, 10X

cadavers presented ADAA. A statistically significant association was found between aortic atherosclerotic disease and Frank's presence (FT 0.029, OR 0.500 [95\% CI 0.354-0.707], $p<0.05)$. The thickness of the adipose cushion of the abdominal wall at the height of the umbilical scar varied from $0.5 \mathrm{~cm}$ to $9.5 \mathrm{~cm}$ (mean of $3.23 \mathrm{~cm}$, median of $2.5 \mathrm{~cm}$ ). In the examination of the heart, the main macroscopic findings were: AMI, cardiac hypertrophy, pericarditis, cardiomegaly and cardiac dilatation.

\section{Histological morphological analysis: FDLV}

FDLV was observed in 38 of the 40 cases analyzed - 95\% of the total (Fig. 2). Considering the different anatomical compartments, the fatty deposit was distributed as follows: 92.5\%, EF (Fig. 3); 82.5\%, PAT (Fig. 3); and 20\% of the cases presented MA (Fig. 3).

It was observed significance with level of association and chance of risk, between the crossing of variables: a) FDLV and EF (FT 0.006; OR 0.032 [95\% CI 0.0050.22 ; $p<0.05$ ); b) PAT and FDLV (FT 0.019; OR 0.097; [95\% CI 0.033-0.284]; $p<0.05$ ); c) $\mathrm{AM}$ and $\mathrm{EF}$ (FT 0.557, OR 0.758 [95\% CI 0.625-0.919], $p<0.05$ ) (Fig. 4).

The microscopic measurement of the thickness of EF in the LV ranged from $0.5 \mathrm{~mm}$ to $7.0 \mathrm{~mm}$ (mean of $2.73 \mathrm{~mm}$, median of $2.4 \mathrm{~mm}$ ), six samples presented thickness greater than or equal to five (Fig. 5). Statistical correlation was observed between the thickness of the epicardial adiposity and the thickness of the abdominal adipose cushion $\left(r^{2}=0.5\right)$.

\section{Histological morphological analysis: FDLV x epidemiological and morphological variables}

The present study showed an association between the presence of FDLV and the following variables: alcoholism, smoking, presence of Frank's Sign, ADAA (FDLV present in $93.94 \%$ of the 33 cadavers with the disease), immediate cause of death - AMI (FDLV present in all cadavers with AMI) and macroscopic finding of cardiac hypertrophy (Table 2).

In this study, EF was seen in $93.94 \%$ of cadavers with ADAA (Fig. 6), and PAT was seen in 31 of the 33 cadavers with ADAA.

\section{Discussion}

In necroscopic studies, cardiac fat is often seen in the $\mathrm{RV}$, with a frequency of up to $85 \%$ [5]. Adipose tissue in the left heart chamber, except at the ventricular apex, in healthy individuals has been rarely reported. The necroscopic finding of adipose tissue in the LV in 95\% of the cases in the present study reinforces the growing evidence that emerged in the last decade from imaging tests, the presence of fat cells in the heart of healthy people, as well as in people with cardiovascular and non-cardiovascular diseases [2].

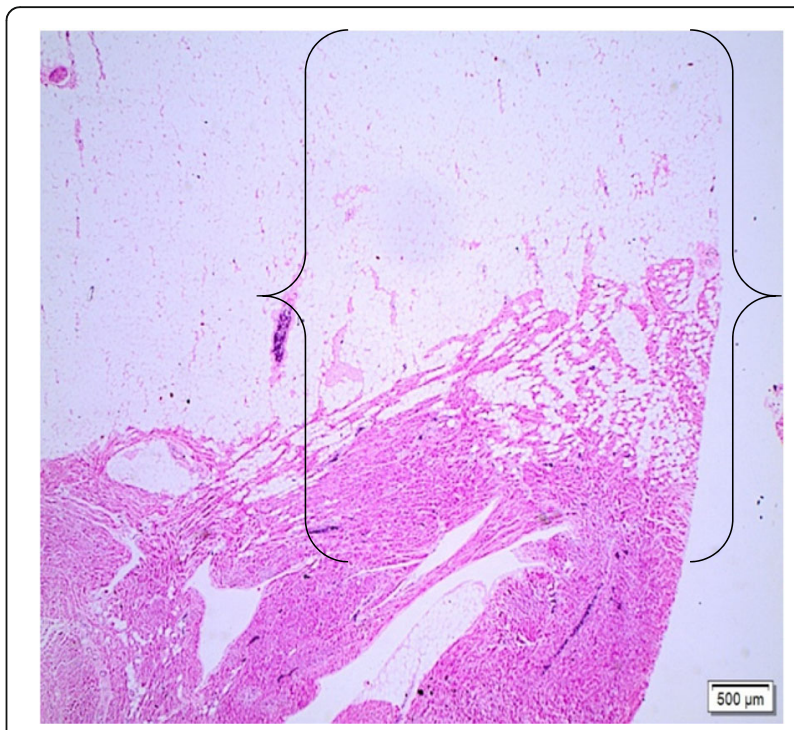

Fig. 4 Photomicrograph showing association between EF and AM of the LV (curly brackets). Legend: Case 7. Hematoxylin-eosin, 4X 


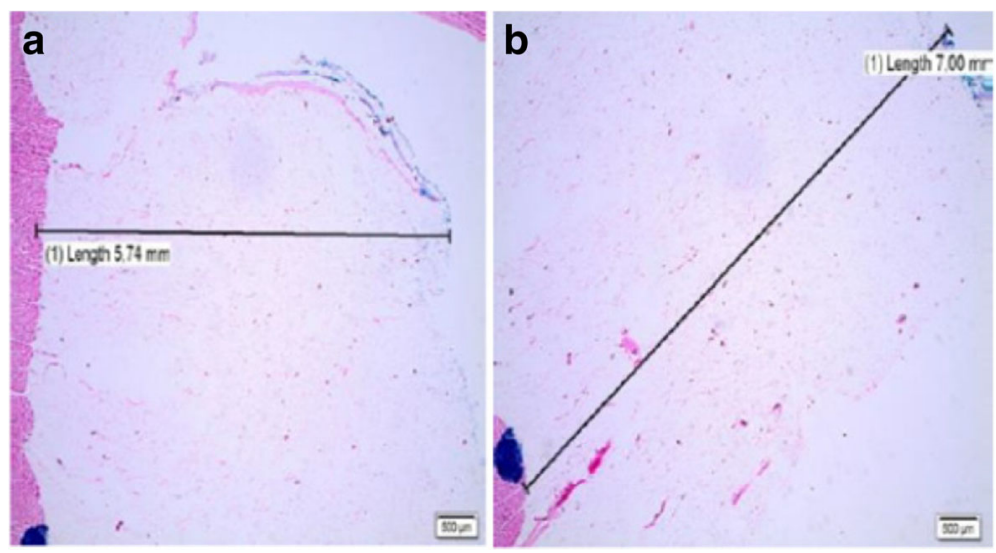

Fig. 5 Photomicrographs showing the measurement of the thickness of the EF in the LV. Legend: a Case $38: 5.74$ mm of fatty epicardial thickness; b Case 19: 7 mm of epicardial adipose thickness. Hematoxylin-eosin, 4X

Studies indicate that MA is predominantly located in the RV, especially in the anterolateral and apical walls, whereas only a small amount is found in the wall of the LV in its apical portion [7, 12, 13]. In agreement with other studies, no fibrosis or signs of inflammation were observed permeating adipocytes interspersed between the myocardial fibers [7, 12, 14-16]. Bertaso et al. [17] emphasized that the excessive amount of EF tissue may lead to the accumulation of interstitial adipose tissue in the myocardium.

Recent research suggests that EF and epicardial adiposity thickness may be associated with extra-cardiac (aortic and carotid) atherosclerotic lesions [18, 19]. It also suggests that fatty deposition in this compartment may represent an additional and even more direct tool for the stratification of cardiovascular risk, because of its anatomy and functional proximity to the coronary circulation [20]. In addition, perivascular fat can locally accelerate the atherosclerotic process, specifically the coronary [21-24].

According to the current knowledge, abnormal values of EF can be considered as thickness greater than $5 \mathrm{~mm}$ [17]. Nelson et al. [25] analyzed the thickness of epicardial adipose tissue through echocardiography and concluded that thicknesses greater than or equal to $5.0 \mathrm{~mm}$ could identify an individual with a higher probability of having detectable carotid atherosclerosis (risk factor for cardiovascular disease). All cardiac samples of this study that presented a thickness greater than or equal to five (6 samples) exhibited aortic atherosclerotic disease. Similar to other works, the results indicate that the thickness of epicardial adipose tissue in obese individuals seems to correlate with the abdominal perimeter [26].

The increase in the FDLV may be related to changes in the lifestyle of the population, related to eating habits and sedentary lifestyle, which resulted in overweight and obesity, with consequent adipose tissue deposition in the organic systems.

The results found between FDLV and epidemiological variables reinforce the correlation of cardiac adiposity with markers of cardiovascular disease risk [9, 27], once the increase in cardiovascular risk is associated with the consumption of elevated alcohol levels [28-31], the presence of Frank's Sign [32, 33] and smoking [34-36]. Recent studies suggest that smoking may have a direct association with fatty cardiac deposition [37, 38].

All cadavers that had AMI as an immediate cause of death presented FDLV. The studies mention a high incidence (68-84\%) between the presence of FDLV and AMI, based on necropsy and imaging results $[39,40]$. In patients with ischemic heart disease, the presence of FDLV was observed in up to $6 \%$ of computed tomography scans [40]. The association measure identified a significant risk chance for these variables.

Table 2 Association between FDLV and epidemiological/morphological variables in cadavers submitted to clinical necropsy

\begin{tabular}{lllll}
\hline Crossing variables & Fisher statistics & ODDS RATIO (OR) & Inferior limit & Upper limit \\
\hline FDLV and alcoholism & 0.04 & 0.161 & 0.072 & 0.36 \\
FDLV and smoking & 0.508 & 0.581 & 0.431 & 0.73 \\
FDLV and Sign of Frank & 0.502 & 0.567 & 0.414 & 0.775 \\
FDLV and ADAA & 1 & 0.774 & 0.640 & 0.936 \\
FDLV and AMI & 1 & 0.730 & 0.600 & 0.888 \\
FDLV and cardiac hypertrophy & 1 & 0.700 & 0.525 & 0.933 \\
\hline
\end{tabular}




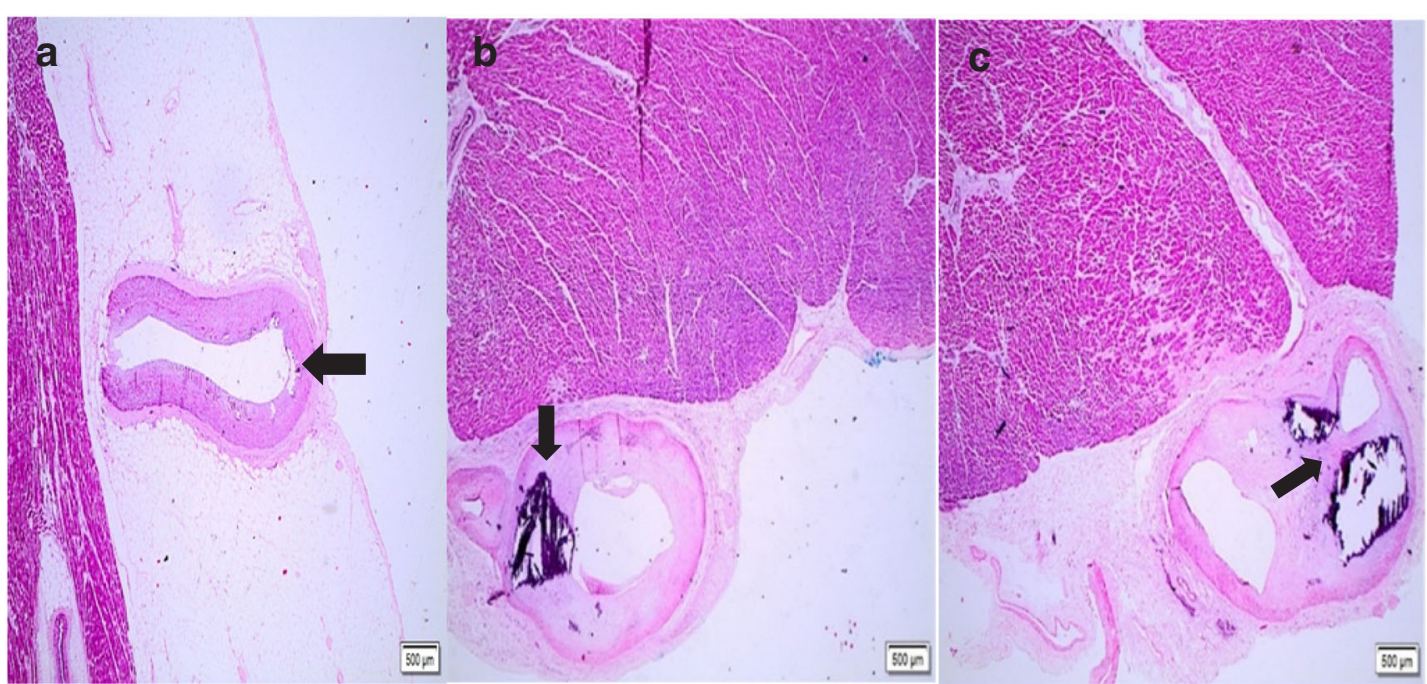

Fig. 6 Photomicrographs showing atherosclerotic disease in vessels located inside the EF of the LV: Legend: a Case 12 showing atheroma plaque (black broad arrow); b Case 22 showing calcified atheroma plaque (black broad arrow); c Case 30 showing atheroma plaque with prominent dystrophic calcification (broad black arrow). Hematoxylin-eosin, 4X

The association found in this study indicates that the FDLV constitutes a direct risk of cardiac hypertrophy. Kaminaga and others [41] concluded that Hypertrophic cardiomyopathy may be associated with the presence of myocardial fat in the LV with a thickened wall. It has recently been inferred that the accumulation of cardiac fat can generate mechanical overload, resulting in a remodeling of the cardiac mass, alteration of the vascular resistance and the ejection fraction [42], with consequent reduction of the LV performance, eccentric modifications of left ventricular chamber, systolic changes and increased tension in the LV wall $[43,44]$. All these anatomical and functional repercussions can be seen from the installation and progression of cardiac hypertrophy.

Likewise, the fatty deposition in the left ventricle was consistently associated with aortic atherosclerosis, being present in $93.94 \%$ of the 33 cadavers carrying the disease. The results corroborate with other studies that reported a potential association between the variables, either independently or indirectly [45-48].

These results show that the FDLV may represent an additional tool for the stratification of cardiovascular risk.

\section{Conclusion}

The results obtained in this work demonstrated that FDLV is frequent, with EF and PAT being the most frequent topographies for fatty accumulation in the left heart chamber. In addition, EF is associated with MA. Furthermore, FDLV is associated with heart diseases such as cardiac hypertrophy and AMI and correlates with the thickness of the abdominal adipose cushion. We believe that cardiac FDLV may represent an additional tool for the stratification of cardiovascular risk and cannot be considered a random necroscopic finding, requiring diagnostic investigation and ascertainment of the clinical implications.

\section{Abbreviations \\ ADAA: Atherosclerotic disease in the ascending aorta; AMI: Acute myocardial infarction; EF: Epicardial fat; FDLV: Fat deposition in the left ventricule; \\ LV: Left ventricle; MA: Myocardial adiposity; PAT: Pericoronary adipose tissue; RV: Right ventricle}

\section{Acknowledgements}

To the Pathologists and technical staff of the Death Verification Service of Recife. The teachers Mariana Montenegro de Melo Lira, Liriane Baratella Evêncio, Manuela Figueiroa Lyra de Freitas and Luciano Tavares Montenegro are gratefully acknowledged.

\section{Funding}

No funding was received.

\section{Availability of data and material}

The datasets used and/or analysed during the current study are available from the corresponding author upon reasonable request.

\section{Authors' contributions}

RMSS conceived the study, carried the collection of data and samples, performed the statistical analysis and drafted the manuscript. RJVM participated in the design of the study, coordination and helped to draft the manuscript. All authors have read and approved the final manuscript.

\section{Competing interests}

The authors declare that they have no competing interests.

\section{Consent for publication}

The publication was authorized by the declaration of consent, provided by the General Directorate of Health Education of the Health Department of the State of Pernambuco, for the use of materials and data collected and through the term of free and informed consent presented to the legal guardian of the deceased person.

\section{Ethics approval and consent to participate}

The execution of the present study was authorized by the General Directorate of Health Education of the Health Department of the State of Pernambuco and approved by the Ethics and Research Committee of the Federal University of 
Pernambuco - CAAE n 46,098,815.7.000.5208. All applicable international, national and/or institutional guidelines were followed.

\section{Author details}

'Pathological Anatomy Service, Lauro Wanderley University Hospital, Federal University of Paraíba, João Pessoa, Paraíba, Brazil. ${ }^{2}$ Postgraduate Program in Pathology, Federal University of Pernambuco, Recife, Brazil. ${ }^{3}$ Department of Pathological Anatomy, Federal University of Pernambuco, Recife, Brazil.

Received: 14 February 2017 Accepted: 25 April 2017 Published online: 02 May 2017

\section{References}

1. Fagundes LA, et al. Cardiomiopatia Arritmogênica do Ventrículo Direito. Valor Preditivo da Dispersão do Intervalo QT para Avaliação de Risco Arritmogênico e de Morte Súbita. Arq Bras Cardiol. 2000;75:115-9.

2. Selthofer-relatić K, Bošnjak I. Myocardial fat as a part of cardiac visceral adipose tissue: physiological and pathophysiological view. J Endocrinol Investig. 2015:8(9):1-7.

3. Baroldi $\mathrm{G}$, et al. Lipomatous metaplasia in left ventricular scar. Can J Cardiol. 1997;13:65-71.

4. Kimura F, et al. Myocardial fat at cardiac imaging: how can we differentiate pathologic from physiologic fatty infiltration? Radiographics. 2010;30:1587-602.

5. De La Grandmaison GL, Le Bihan C, Durigon M. Assessment of right ventricular lipomatosis by histomorphometry in control adult autopsy cases. Int J Legal Med. 2001;115:105-8.

6. Kim S, Ko SM, Song MG. Linear fat deposition in the middle layer of the left ventricular myocardium: computed tomographic findings. Korean J Radiol. 2010;11:571-3

7. Tansey D, Aly Z, Sheppard MN. Fat in the right ventricle of the normal heart. Histopathology. 2005;46:98-104.

8. Godinez-valdez $\mathrm{H}$, et al. Cardiac rupture in a patient with an acute myocardial infarction and extensive fatty infiltration of the heart ("adipositas cordis"). Int J Cardiol. 2012;154:62-4.

9. Mckenna J, et al. Diagnosis of arrhythmogenic right ventricular dysplasia/ cardiomyopathy. Task force of the working group myocardial and Pericardial disease of the European Society of Cardiology and of the scientific council on Cardiomyopathies of the international society and Federation of Cardiology. Br Heart J. 1994;71:215.

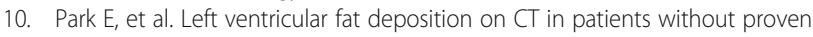
myocardial disease. Int J Cardiovasc Imaging. 2013;29:37-45.

11. Wang $\mathrm{H}$, et al. The autopsy study of 553 cases of sudden cardiac death in Chinese adults. Heart Vessel. 2013;29(4):1-10.

12. Basso C, Thiene G. Adipositas cordis, fatty infiltration of the right ventricle, and arrhythmogenic right ventricular cardiomyopathy. Just a matter of fat? Cardiovasc Pathol. 2005;14:37-41.

13. Kim E, et al. Right ventricular fat infiltration in asymptomatic subjects: observations from ECG-gated 16-slice multidetector CT. J Comput Assist Tomogr. 2007:31:22-8.

14. Fontaine $\mathrm{G}$, et al. Fat in the heart. A feature unique to the human species? Observational reflections on an unsolved problem. Acta Cardiol. 1999;54: 189-94.

15. Goldfarb W, Roth M, Han J. Myocardial fat deposition after left ventricular myocardial infarction: assessment by using MR water-fat separation imaging. Radiology. 2009;253:65-73.

16. Goldfarb W, et al. T1-weighted magnetic resonance imaging shows fatty deposition after myocardial infarction. Magn Reson Med. 2007;57:828-34.

17. Bertaso GA, et al. Gordura epicárdica: definição, medidas e revisão sistemática dos principais desfechos. Arquivos brasileiros de cardiologia. São Paulo. 2013;101:18-28.

18. Baragetti, A, et al. Subclinical atherosclerosis is associated with Epicardial fat thickness and hepatic steatosis in the general population. Nutrition, metabolism and cardiovascular diseases. 2015.

19. Yorgun $\mathrm{H}$, et al. Epicardial adipose tissue thickness predicts descending thoracic aorta atherosclerosis shown by multidetector computed tomography. International J Cardiovasc Imaging. 2012;28:911-9.

20. Katsiki N, Mikhailidis P, Wierzbicki S. Epicardial fat and vascular risk: a narrative review. Curr Opin Cardiol. 2013;28:458-63.

21. Mazurek T, et al. Human epicardial adipose tissue is a source of inflammatory mediators. Circulation. 2003;108:2460-6.
22. Rajsheker $\mathrm{S}$, et al. Crosstalk between perivascular adipose tissue and blood vessels. Curr Opin Pharmacol. 2010;10:191-6.

23. Hirata $Y$, et al. Enhanced inflammation in epicardial fat in patients with coronary artery disease. Int Heart J. 2011;52:139-42.

24. Demircelik MB, et al. Epicardial adipose tissue and pericoronary fat thickness measured with 64-multidetector computed tomography: potential predictors of the severity of coronary artery disease. Clinics. 2014;69:388-92.

25. Nelson R, et al. Epicardial fat: an additional measurement for subclinical atherosclerosis and cardiovascular risk stratification? J Am Soc Echocardiogr. 2011;24:339-45.

26. Foppa $M$, et al. Subcutaneous fat thickness, but not epicardial fat thickness, parallels weight reduction three months after bariatric surgery: a cardiac magnetic resonance study. Int J Cardiol. 2013;168:4532-3.

27. Liu J, et al. Pericardial adipose tissue, atherosclerosis, and cardiovascular disease risk factors the Jackson heart study. Diabetes Care. 2010;33:1635-9.

28. Gordon T, Kannel B. Drinking habits and cardiovascular disease: the Framingham study. Am Heart J. 1983;105:667-73.

29. O'KEEFE, James $H$, et al. Alcohol and cardiovascular health: the dose makes the poison... or the remedy. In: Mayo Clinic Proceedings. Elsevier. 2014; 89(3):382-393.

30. Fernández-solà J. Cardiovascular risks and benefits of moderate and heavy alcohol consumption. Nat Rev Cardiol. 2015:12:576-87.

31. Mostofsky $E$, et al. Alcohol and immediate risk of cardiovascular events a systematic review and dose-response meta-analysis. Circulation. 2016;133:979-87.

32. Kirkham N, et al. Diagonal earlobe creases and fatal cardiovascular disease: a necropsy study. Br Heart J. 1989;61:361-4.

33. Edston $\mathrm{E}$. The earlobe crease, coronary artery disease, and sudden cardiac death: an autopsy study of 520 individuals. Am J Forensic Med Pathol. 2006; 27:129-33.

34. Larsson $\mathrm{B}$, et al. Abdominal adipose tissue distribution, obesity, and risk of cardiovascular disease and death: 13 year follow up of participants in the study of men born in 1913. Br Med J (Clin Res Ed). 1984;288:1401-4.

35. Kannel WB, D'agostino RB, Belanger AJ. Fibrinogen, cigarette smoking, and risk of cardiovascular disease: insights from the Framingham study. Am Heart J. 1987;113:1006-10.

36. Ambrose JA, Barua RS. The pathophysiology of cigarette smoking and cardiovascular disease: an update. J Am Coll Cardiol. 2004;43:1731-7.

37. Monti $\mathrm{M}$, et al. Correlation between epicardial fat and cigarette smoking: $\mathrm{CT}$ imaging in patients with metabolic syndrome. Scand Cardiovasc J. 2014;48:317-22.

38. Orban $\mathrm{M}$, et al. Association between tobacco smoking and proinflammatory humoral signalling in human epicardial adipose tissue: a prospective cohort study in patients undergoing major cardiac surgery. Chest J. 2016;150:1304A-1304A.

39. Su L, Siegel JE, Fishbein MC. Adipose tissue in myocardial infarction. Cardiovasc Pathol. 2004;13:98-102.

40. Zafar HM, Litt HI, Torigian DA. CT imaging features and frequency of left ventricular myocardial fat in patients with $C T$ findings of chronic left ventricular myocardial infarction. Clin Radiol. 2008;63:256-62.

41. Kaminaga $T$, et al. Detection of myocardial fatty components with ultrafast CT. Nippon Acta Radiol. 1993:53:28-34.

42. Iozzo P. Myocardial, perivascular, and epicardial fat. Diabetes Care. 2011;34:371-9.

43. Paradise NF, et al. Left ventricular function of the isolated, genetically obese rat's heart. Am J Phys Heart Circ Phys. 1985;248:438-44.

44. Zhou YT, et al. Lipotoxic heart disease in obese rats: implications for human obesity. Proc Natl Acad Sci. 2000;97:1784-9.

45. Rosito GA, et al. Pericardial fat, visceral abdominal fat, cardiovascular disease risk factors, and vascular calcification in a community-based sample the Framingham heart study. Circulation. 2008;117:605-13.

46. lacobellis G, Willens HJ. Echocardiographic epicardial fat: a review of research and clinical applications. J Am Soc Echocardiogr. 2009;22:1311-9.

47. $\mathrm{Xu} Y$, et al. How to interpret epicardial adipose tissue as a cause of coronary artery disease: a meta-analysis. Coron Artery Dis. 2012;23:227-33.

48. Lee HY, Després J, Koh KK. Perivascular adipose tissue in the pathogenesis of cardiovascular disease. Atherosclerosis. 2013;230:177-84. 